\title{
EXPERIMENTAL METHODOLOGY AIMED AT IMPROVING THE FRONT-LEG KICK SPEED IN KARATE
}

\author{
Radoslav Penov, Milen Chalakov \\ National Sports Academy „Vassil Levski”, Sofia, Bulgaria
}

\begin{abstract}
That article aims to present the development of an experimental methodology that improves the speed of kicks in Karate. The rationale behind creating the methodology is the fact that the speed of kicks in Karate is instrumental for overcoming the opponent. In addition, kicks are among the most commonly used techniques in matches. Therefore, our goal was to study the effect of applying the methodology we created onto improving the speed of kicks in Karate. In order to conduct the study, we used a video-computerized system to record and analyze the speed of kicks performed by the participants in the experiment. The results concerning the speeds of kicks were measured in identical ways in order to make sure that the survey was performed under uniform conditions. The input data was processed by means of kinematics analysis software. To prove the credibility of the data registered, we applied the necessary statistical analysis methods.

We hope that by applying the methodology that we developed and have presented in this article, more coaches will start using modern tools and methods in order to improve the quality of the training process in Karate.
\end{abstract}

Key words: methodology, karate, kick, leg, speed.

\section{INTRODUCTION}

Modern Karate employs a variety of kicks, which is in fact specific for this sport. Kicks are performed at three different levels of height: low, middle, and high (gedan, chudan, and jodan). The use of kicks at high maneuverability and dynamics in rapidly changing circumstances requires of competitors ultimately specialized technical preparation and physical and psychological strength (Bishop, 1989; Higaonna, 1985).

Kicks are harder to perform than punches because remaining balanced on unstable surfaces is difficult; however, once properly performed, a kick can produce unrivaled power, precision, speed and damage (Habersetzer, 1998).

Karate stances strictly define the body posture at specific positions of arms and legs. In Shotokan karate all transitions are performed by shifting from one stance to another (Cynarski et al, 2014 ). Punches and kicks can be se- parated into the following phases:

1. Swing - this as an action that precedes the punch or kick and leads to increasing the distance between the body part that should implement the strike and the target.

2. Striking action - this is the motion from the final point of the swing and the point of impact.

3. Striking impact - the contact between the two bodies.

4. Motion after the impact - the motion of the body part that delivered the strike after disengaging from contact with the target.

The coordination of motions in the case of techniques of greatest power meets the following two expectations (Pinto, et al. 2007):

1. Gaining maximum velocity for the body part that should perform the strike before before phase three.

2. Increasing the strike's impact at the moment of impact by hardening specific areas 
of the striking limb through simultaneously employing the antagonistic muscles and increasing the radius of rotation.

In order to increase and further improve Karate techniques, athletes should perform each technique repeatedly, with maximum concentration and dedication. This, however, will not be enough unless the training is based on proper physical and physiological principles (Marques, 2014). Utilizing the individual preparation of the athlete while training is another important factor that helps improve the technique. This factor contributes to the improvement of techniques not only in karate but in other single fights. (Iliev, 2016).

\section{Goals of the study}

This survey aims to study the effect of applying this methodology for the purposeful increase of the speed of the front-leg kick Kizami Mawashi Geri.

\section{Objectives of the study}

1. To evaluate the importance of the speed of kicks and punches for the technical mastery of Karate.

2. To develop a methodology for purposeful development of the speed of kicks and punches.

3. To analyze the effect of the methodology for purposeful development of the speed of kicks and punches.

\section{Methodology}

The survey was conducted by means of videocomputerized system for registration and analysis of the Karate kicks and punches. Ten male participants, aged 19 to 26, took part.
All participants compete in Karate on the National Sports Academy's team and possess technical levels from 5th kyu to 1 st dan.

Competitors surveyed:

1. I.S. - National champion for 2017, $3 \mathrm{kyu}$, brown belt.

2. D.N. - National champion for 2017, 3 dan, black belt.

3. M.M. - National champion 2018, 2 dan, black belt.

4. E.K. - National Championship (third place) 2017, blue belt.

5. N.N. - National champion - Team 2017, 5 kyu, blue belt.

6. A.T. - National champion for 2014, 1 dan, black belt.

7. S.S. - National champion 2017, 1 dan, black belt.

8. V.G. - National champion 2016, 3 dan, black belt.

9. M.M. - National champion 2012, 1 dan, black belt.

10. G.A. - National champion 2013, 1 dan, black belt.

To accomplish the tasks assigned, the athletes in question were divided into two groups: a control group and an experiment group. Both groups performed 10 kicks onto a designated target, and we recorded precisely the results achieved. For a period of five months, we applied a special experimental methodology onto the experimental group in order to develop the physical quality of kick-speed. The methodology used is presented in Tables 2 and 3.

The grouping of the participants is presented in Table 1.

Table 1. Group organization

\begin{tabular}{cc}
\hline Control group & Test group \\
\hline I.S. & A.T. \\
D.N. & M.M. \\
N.N. & V.G. \\
S.S. & E.K. \\
G.A. & M.M.
\end{tabular}


The exercises applied to the test group, (Kizami Mawashi Geri) are presented in Table aiming to develop speed of the front-leg kick 2 .

Table 2. Dosage per exercise (aiming to develop the speed of the front-leg kick, Kizami Mawashi Geri)

\begin{tabular}{|c|c|c|c|c|c|c|c|}
\hline Exercise & $\begin{array}{c}\text { Month } \\
\text { Weekly } \\
\text { dosage }\end{array}$ & I & II & III & IV & $\mathbf{V}$ & VI \\
\hline $\begin{array}{l}\text { 1. Half-squat with } \\
\text { a bar and a hop }\end{array}$ & $\begin{array}{l}\text { week } 1 \\
\text { week } 2 \\
\text { week } 3 \\
\text { week } 4 \\
\end{array}$ & $\begin{array}{l}2 \times 10 \\
2 \times 10 \\
2 \times 10 \\
2 \times 10 \\
\end{array}$ & $\begin{array}{l}3 \times 10 \\
3 \times 10 \\
3 \times 10 \\
3 \times 10 \\
\end{array}$ & $\begin{array}{l}4 \times 10 \\
4 \times 10 \\
4 X 10 \\
4 X 10 \\
\end{array}$ & $\begin{array}{l}5 \times 10 \\
5 \times 10 \\
5 \times 10 \\
5 \times 10 \\
\end{array}$ & $\begin{array}{l}4 \mathrm{X} 10 \\
4 \mathrm{X} 10 \\
4 \mathrm{X} 10 \\
4\end{array}$ & $\begin{array}{l}3 \times 10 \\
3 \times 10 \\
3 \times 10 \\
3 \times 10 \\
\end{array}$ \\
\hline $\begin{array}{l}\text { 2. Standing long } \\
\text { jump }\end{array}$ & $\begin{array}{l}\text { week } 1 \\
\text { week } 2 \\
\text { week } 3 \\
\text { week } 4 \\
\end{array}$ & $\begin{array}{l}2 \times 10 \\
2 \times 10 \\
2 \times 10 \\
2 \times 10 \\
\end{array}$ & $\begin{array}{l}3 \times 10 \\
3 \times 10 \\
3 X 10 \\
3 X 10 \\
\end{array}$ & $\begin{array}{l}4 \times 10 \\
4 X 10 \\
4 X 10 \\
4 X 10 \\
\end{array}$ & $\begin{array}{l}\mathrm{X} 8 \\
5 \times 8 \\
5 \times 8 \\
5 \times 8 \\
\end{array}$ & $\begin{array}{l}5 \times 6 \\
5 \times 6 \\
5 \times 6 \\
5 \times 6 \\
\end{array}$ & $\begin{array}{l}3 \times 5 \\
3 \times 5 \\
3 \times 5 \\
3 \times 5 \\
\end{array}$ \\
\hline $\begin{array}{l}\text { 3. Performing } \\
\text { Mawashi Geri } \\
\text { with an elastic } \\
\text { band }\end{array}$ & $\begin{array}{l}\text { week } 1 \\
\text { week } 2 \\
\text { week } 3 \\
\text { week } 4\end{array}$ & $\begin{array}{l}2 \times 5 \\
2 \times 5 \\
2 X 5 \\
2 X 5\end{array}$ & $\begin{array}{l}3 \times 5 \\
3 \times 5 \\
3 \times 5 \\
3 \times 5\end{array}$ & $\begin{array}{l}4 X 5 \\
4 X 5 \\
4 X 5 \\
4 X 5\end{array}$ & $\begin{array}{l}5 \times 5 \\
5 \times 5 \\
5 \times 5 \\
5 \times 5\end{array}$ & $\begin{array}{l}4 \times 5 \\
4 \times 5 \\
4 \times 5 \\
4 \times 5\end{array}$ & $\begin{array}{l}3 \times 5 \\
3 \times 5 \\
3 \times 5 \\
3 \times 5\end{array}$ \\
\hline 4. Splits & $\begin{array}{l}\text { week } 1 \\
\text { week } 2 \\
\text { week } 3 \\
\text { week } 4 \\
\end{array}$ & $\begin{array}{l}2 \times 30 \\
2 \times 30 \\
3 \times 30 \\
3 \times 30 \\
\end{array}$ & $\begin{array}{l}2 \mathrm{X} 45 \\
2 \mathrm{X} 45 \\
3 \mathrm{X} 45 \\
3 \mathrm{X} 45 \\
\end{array}$ & $\begin{array}{l}3 \times 45 \\
3 \times 60 \\
3 \times 60 \\
4 X 60 \\
\end{array}$ & $\begin{array}{l}\times 60 \\
5 \times 60 \\
5 \times 60 \\
5 \times 60 \\
\end{array}$ & $\begin{array}{l}5 \times 60 \\
5 \times 60 \\
5 \times 60 \\
5 \times 60 \\
\end{array}$ & $\begin{array}{l}5 \times 60 \\
5 \times 60 \\
5 \times 60 \\
5 \times 60 \\
\end{array}$ \\
\hline $\begin{array}{l}\text { 5. Performing } \\
\text { maximum number } \\
\text { of Mawashi Geri } \\
\text { repetitions per } 10 \\
\text { seconds. }\end{array}$ & $\begin{array}{l}\text { week } 1 \\
\text { week } 2 \\
\text { week } 3 \\
\text { week } 4\end{array}$ & $\begin{array}{l}2 \times 10 \\
2 \times 10 \\
2 \times 10 \\
2 \times 10\end{array}$ & $\begin{array}{l}3 \times 10 \\
3 \times 10 \\
3 \times 10 \\
3 \times 10\end{array}$ & $\begin{array}{l}4 \times 10 \\
4 X 10 \\
4 X 10 \\
4 X 10\end{array}$ & $\begin{array}{l}5 \times 10 \\
5 \times 10 \\
5 \times 10 \\
5 \times 10\end{array}$ & $\begin{array}{l}3 \times 10 \\
3 X 10 \\
3 X 10 \\
3 X 10\end{array}$ & $\begin{array}{l}2 \times 10 \\
2 \mathrm{X} 10 \\
2 \mathrm{X} 10 \\
2 \mathrm{X} 10\end{array}$ \\
\hline $\begin{array}{l}\text { 6. Mawashi feint, } \\
\text { step, mawashi } \\
\text { geri - maximum } \\
\text { repetitions per } 10 \\
\text { seconds }\end{array}$ & $\begin{array}{l}\text { week } 1 \\
\text { week } 2 \\
\text { week } 3 \\
\text { week } 4\end{array}$ & $\begin{array}{l}2 \times 10 \\
3 \times 10 \\
4 \times 10 \\
4 X 10\end{array}$ & $\begin{array}{l}4 \times 10 \\
4 X 10 \\
4 X 10 \\
4 X 10\end{array}$ & $\begin{array}{l}2 \mathrm{X} 10 \\
2 \mathrm{X} 10 \\
2 \mathrm{X} 10 \\
2 \mathrm{X} 10\end{array}$ & $\begin{array}{l}2 \mathrm{X} 10 \\
2 \mathrm{X} 10 \\
2 \mathrm{X} 10 \\
2 \mathrm{X} 10\end{array}$ & $\begin{array}{l}2 \mathrm{X} 10 \\
2 \mathrm{X} 10 \\
2 \mathrm{X} 10 \\
2 \mathrm{X} 10\end{array}$ & $\begin{array}{l}1 \mathrm{X} 10 \\
1 \mathrm{X} 10 \\
1 \mathrm{X} 10 \\
1 \mathrm{X} 10\end{array}$ \\
\hline
\end{tabular}

Descriptions of the exercises used by the experimental group in order to develop speed when performing Kizami Mawashi Geri:

1. Half squat and hop - The exercise is performed by using an extra weight bar. The intensity is $40-50 \%$ of $\mathrm{F}_{\max }$. The maximum weight used in this exercise for a single repeat needs to be measured first. Then, for each of the tested persons, the workload for this exercise, which is $40 \%$ of the maximum weight, is determined. The exercise is performed by using a different load for each participant in the experimental group. This exercise builds the explosive strength of the lower limbs and is performed in series of 10 repetitions.

2. Standing long jump - This exercise develops the explosive power of the lower limbs. It is performed after a very good general and special warm-up. One series includes 10 repetitions during the first three months. The repetitions in the following three months reduce to 8,6,5 repetitions per series. The intermission between series is 1 minute. The athlete performs a long jump from the starting position, then faces backwards and performs another long jump towards the starting 
position, and then repeats the action. As the dosage table indicates for this exercise, from month 1 to month 5 the number of the series increases.

3. Performing Mawashi Geri with an elastic band. This exercise develops the explosive power and speed of the lower limbs. It is performed after a very good general and special warm-up. While performing the exercise the athlete uses an elastic band, which is tied to the ankle of the kicking leg, and a partner who holds a punching pad at the level of the head. The athlete performs a front-leg kick targeting the punching pad. The bands used are 8 (eight) millimeters thick with resistance of five kilograms. There are 5 repetitions in each series, and the intermission between the series is from $30 \mathrm{sec}$ to $1 \mathrm{~min}$. The number of series increases during the first four months and then decreases in the months that follow.

4. Splits - This exercise is performed after a very good general warm-up. Once a stand is taken, the athlete positions his/her feet to the side so that the center of body mass be positioned on the virtual line connecting the two heels. At the position of maximum reach, the distance from the symphysis to the ground is measured. This exercise indicates the agility of the hip joint and the flexibility of the muscles of the inner side of the thigh. A gymnast bench or wall can be used as props while shifting the body mass center downwards. The result is measured in centimeters. This exercise develops the flexibility of the lower limbs. The dosage per series varies from 30 to 60 seconds. The number of series increases and goes up to 5 in the final months. This exercise is performed at the end of the training session.

5. Performing a maximum number of Mawashi Geri Kicks per 10 seconds. This is one of the special exercises that devel- ops the specific speed of the lower limbs, and particularly the front-leg hook kick at the level of the head (Kizami Mawashi Geri Jodan). The exercise is performed in pairs as one partner holds a punching pad at the level of the belt, and the other one tries to perform as many repetitions as possible in 10 seconds. The coach measures the time and signals the beginning and the end of the interval. The exercise is performed from a static position, as the partner holding the boxing pad has taken a static position "battle stand". The intermission between the series is 1 minute. From the table with the dosage of this exercise, it is evident that the amount of the series increases from month 1 to month 3 and that it decreases from month 4 to month 6 .

6. A Mawashi Geri feint, step, Mawashi Geri-maximum number of repetitions per 10 seconds. This is a specialized exercise that develops the speed of the lower limbs. The exercise is performed in pairs as one partner holds a punching pad at the level of the head, and the other one performs a Mawashi Geri feint, then performs Kizami Mawashi Geri, and then switches the guard position. The athlete aims to perform as many repetitions as possible in 10 seconds. The exercise is performed from a static position, as the partner holding the boxing pad has taken a static position - "battle stand". The coach measures the time and signals the beginning and the end of the interval. The intermission between the series is 1 minute. From the table with the dosage of this exercise, it is evident that the amount of the series increases from month 1 to month 3 and that it decreases from month 4 to month 6 .

The exercises used by the control group, aiming to develop speed of the front-leg kick (Kizami Mawashi Geri) are presented in Table 3. 
Table 3. Dosage per exercise (aiming to develop the speed of the front-leg kick, Kizami Mawashi Geri)

\begin{tabular}{|c|c|c|c|c|c|c|}
\hline Exercise & $\begin{array}{l}\text { Month } \\
\text { Weekly } \\
\text { dosage } \\
\end{array}$ & $\mathbf{I}$ & II & III & IV & $\mathbf{V}$ \\
\hline \multirow{4}{*}{ 1. 50-meter sprint } & week 1 & $2 \times 30$ & $4 \times 30$ & $5 \times 30$ & $6 \times 30$ & $7 \times 30$ \\
\hline & week 2 & $3 \times 30$ & $5 \times 30$ & $6 \times 30$ & $7 X 30$ & $8 \times 30$ \\
\hline & week 3 & $4 \times 30$ & $5 \times 30$ & $6 \times 30$ & $7 X 30$ & $8 \times 30$ \\
\hline & week 4 & $4 \times 30$ & $5 \times 30$ & $6 \times 30$ & $7 \times 30$ & $8 \times 30$ \\
\hline \multirow{4}{*}{ 2. Standing long jump } & week 1 & $2 \times 5$ & $3 \times 5$ & $4 \times 5$ & $5 \times 5$ & $6 \times 5$ \\
\hline & week 2 & $3 \times 5$ & $4 \times 5$ & $5 \times 5$ & $6 \times 5$ & $7 \times 5$ \\
\hline & week 3 & $3 \times 5$ & $4 X 5$ & $5 \times 5$ & $6 \times 5$ & $7 \times 5$ \\
\hline & week 4 & $3 \times 5$ & $4 \times 5$ & $5 \times 5$ & $6 \times 5$ & $7 X 5$ \\
\hline \multirow{4}{*}{ 3. 3-6-9 Shuttle } & week 1 & $2 \times 3-6-9$ & $3 \times 3-6-9$ & $4 \times 3-6-9$ & $5 \times 3-6-9$ & $6 \times 3-6-9$ \\
\hline & week 2 & $2 \times 3-6-9$ & $3 \times 3-6-9$ & $4 \times 3-6-9$ & $5 \times 3-6-9$ & $6 \times 3-6-9$ \\
\hline & week 3 & $2 \times 3-6-9$ & $3 \times 3-6-9$ & $4 \times 3-6-9$ & $5 \times 3-6-9$ & $6 \times 3-6-9$ \\
\hline & week 4 & $2 \times 3-6-9$ & $3 \times 3-6-9$ & $4 \times 3-6-9$ & $5 \times 3-6-9$ & $6 \times 3-6-9$ \\
\hline \multirow{4}{*}{$\begin{array}{l}\text { 4. Kizami Mawashi } \\
\text { Geri - performed in } \\
\text { pairs upon signal }\end{array}$} & week 1 & $2 X 5$ & $3 \times 10$ & $3 \times 10$ & $3 \times 10$ & $3 \times 10$ \\
\hline & week 2 & $2 \times 5$ & $3 \times 10$ & $3 \times 10$ & $3 \times 10$ & $3 \times 10$ \\
\hline & week 3 & $2 \times 5$ & $3 \times 10$ & $3 \times 10$ & $3 \times 10$ & $3 \times 10$ \\
\hline & week 4 & $2 \times 5$ & $3 \times 10$ & $3 \times 10$ & $3 \times 10$ & $3 \times 10$ \\
\hline
\end{tabular}

Descriptions of the exercises used by the control group in order to develop speed when performing Kizami Mawashi Geri:

1. 50-meter sprint - This exercise aims to develop the quality of speed. It is performed from a low-start position upon the coach's signal at the maximum speed possible. The exercise is performed in series with a 1-minute break between the series. The exercise is performed after a very good general and special warmup. It is evident from the table with the dosage of this exercise that from month 1 to month 5 the number of the series increases.

2. Standing long jump - This exercise develops the explosive power of the lower limbs. It is performed after a very good general and special warm-up. One series includes 5 repetitions. The intermission between series is from 30 seconds to 1 minute. The athlete performs a long jump from the starting position, then faces backwards and performs another long jump towards the starting position. A total of 5 repetitions are performed. As the dosage table indicates for this exercise, from month 1 to month 5 the number of the series increases.
3. 3-6-9 Shuttle running. This exercise of shuttle running is performed from low-start position upon the coach's signal. The athlete sprints from the starting point to the 3-meter mark, then sprints back to the starting point, sprints to the 6-meter mark, sprints back to the starting point, and sprints to the 9-meter marker and back. This exercise develops speed and agility. It is performed after a very good general and special warm-up. The intermission between the series is 2 minutes. It is evident from the table with the dosage of this exercise that from month 1 to month 5 the overall amount of series increases.

4. Kizami Mawashi Geri - performed in pairs upon signal. This exercise is performed after a very good general and special warm-up. At the start of the exercise the athletes pair up with a partner, and as the coach gives the starting signal one of the athletes performs Kizami Mawashi Geri at full speed from a static position. Athletes alternate performing the kick without interfering with each other with defensive actions. This exercise develops the speed of the lower limbs and a faster auditory reaction. 
The results concerning the speed of the frontleg kick for both groups were measured in the same way in order for the survey to be conducted under identical conditions for both groups. The data regarding the speed was discussed with specialists in order to eliminate mistakes. Kick speeds were registered by means of Sony PJ740 video camera at 50 frames per second. The camera was positioned perpendicularly to the sagittal axis, and the point of view was at the height of the kicks. Later the video recordings were processed by means of Kinovea video-computerized software for cinematic analysis. Only attempts that met the criteria for the speed of the kick were chosen for thorough analysis. The data was normalized regarding the periods of the phases of motion and later averaged (Rathee et. al., 2014). The results that were received from the video-recorded materials were processed with mathematical and statistical methods, including variation analysis.

\section{RESULTS}

The speed of kicks and punches in $\mathrm{Ka}$ rate depends on the proper execution of all phases of performing the technique. Figure 1 illustrates the phases of the kick that was performed by the participants and video recorded. Later, all attempts performed were compared with the proper execution of the kick.

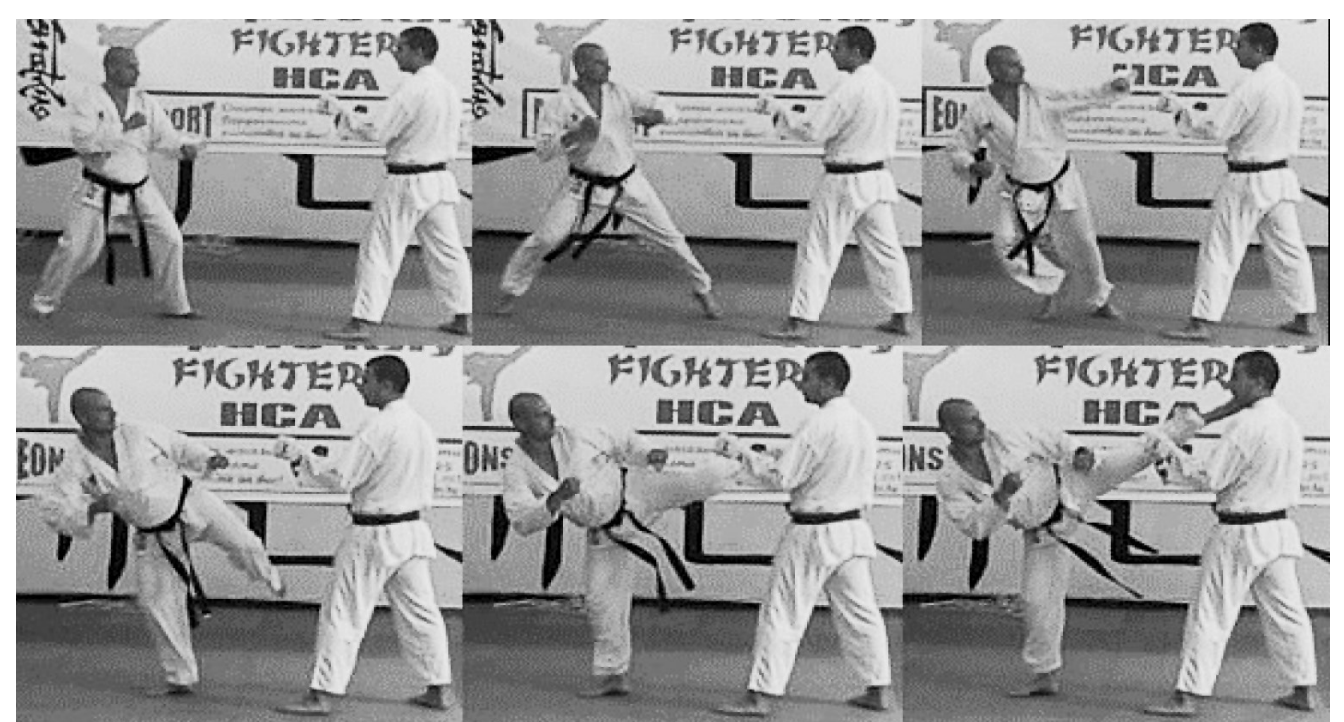

Figure 1. Phases of Kizami Mawashi Geri

After conducting the first and the second measurement of the kick's speed parameters, we received the following data for the control group and the experimental group, as indicated in Figure 2 and Figure 3.

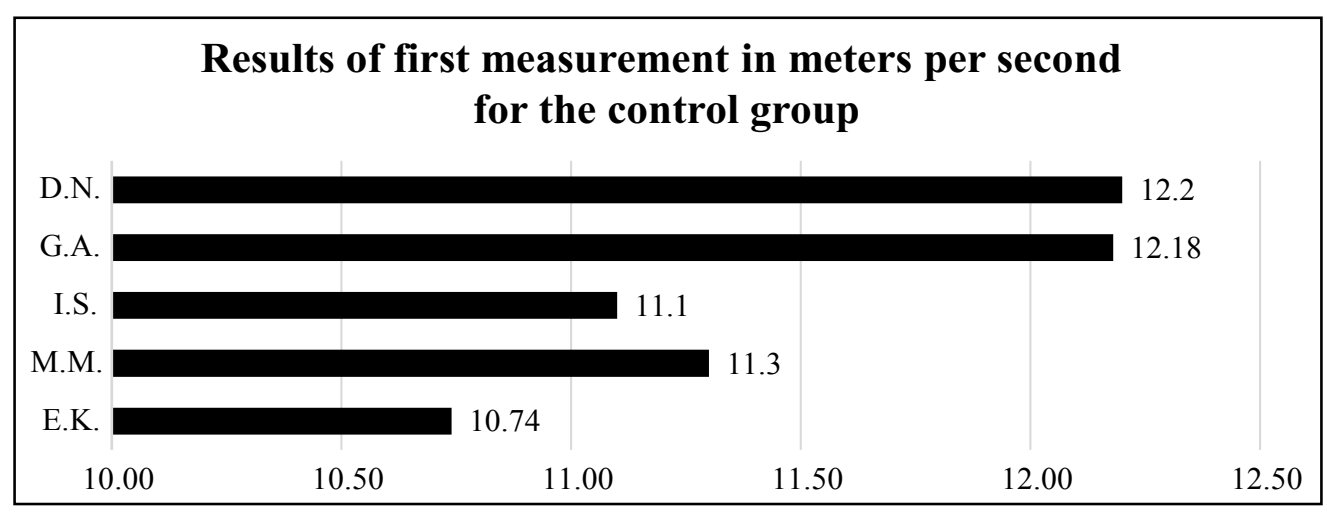

Figure 2. Average kick speeds from the first measurement 


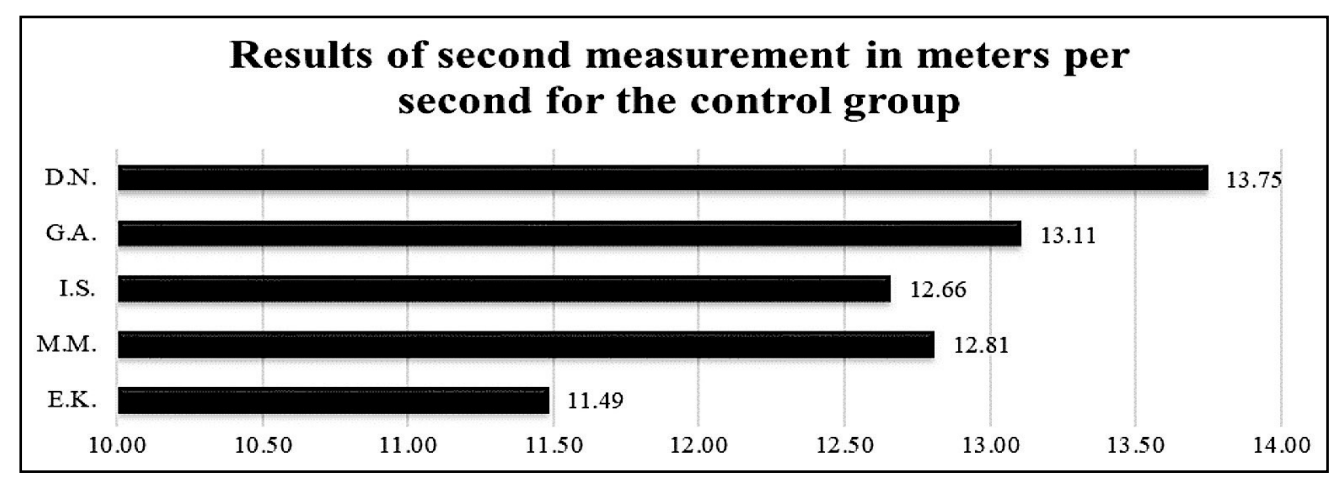

Figure 3. Average kick speeds from the second measurement

After the first and the second measurements following results for the test group. These reof the kick's speed parameters, we received the sults are shown in Figure 4 and Figure 5.

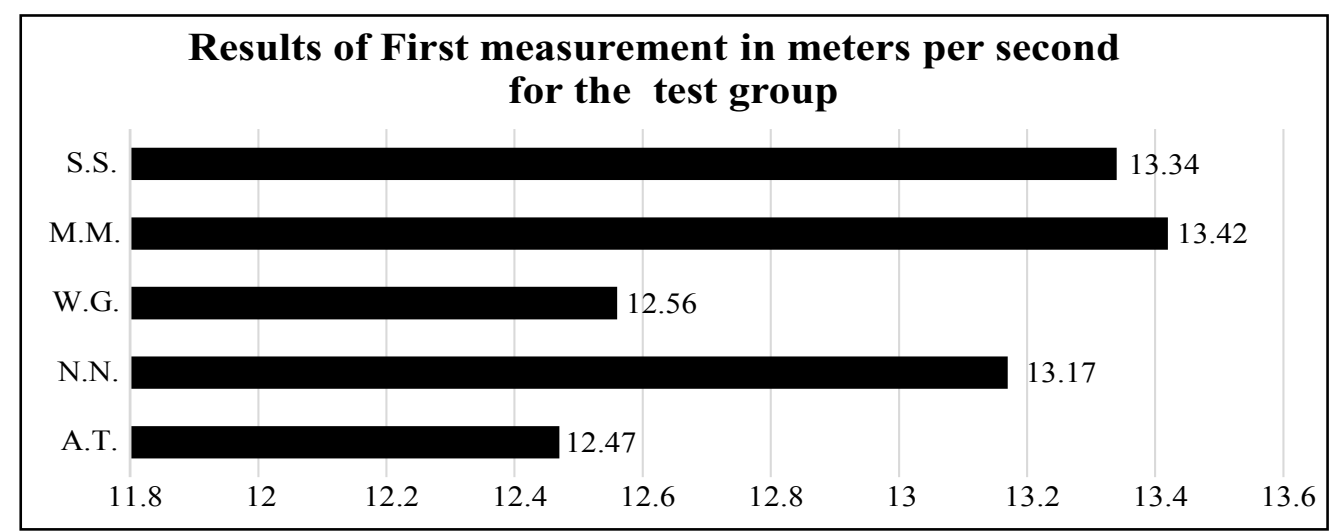

Figure 4. Average kick speeds for the first measurement

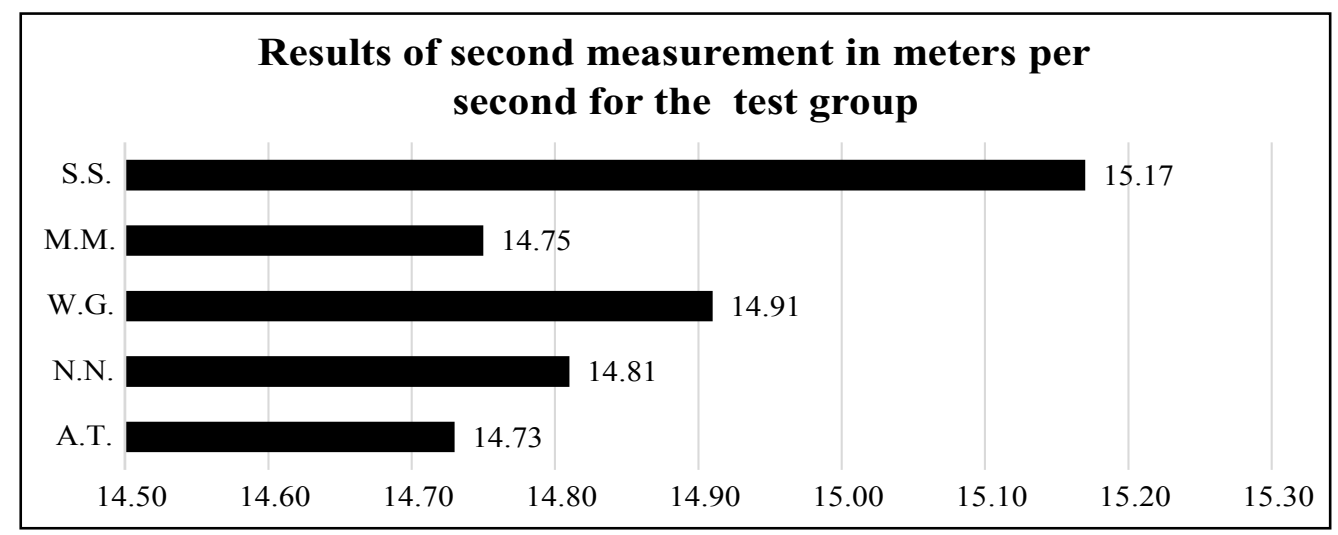

Figure 5. Average kick speeds for the second measurement

Studying the speed of the front-leg kick in Karate is an important aspect of the training process and relates both to the proper execution of the kick and the inability of the opponent to attempt defensive actions. Therefore, it was important for us to prove that the developed methodology leads to increasing the speed of the front-leg kick in Karate.
As a result of the training process that applied the methodology we developed, we achieved improvements of the speed parameters of the kick. The results we received are to be provided in the materials to follow.

For the past period of training, in the control group we observed an increase of the kick's speed by $1.26 \mathrm{~m} / \mathrm{s}$. These results are shown in Figure 6 . 


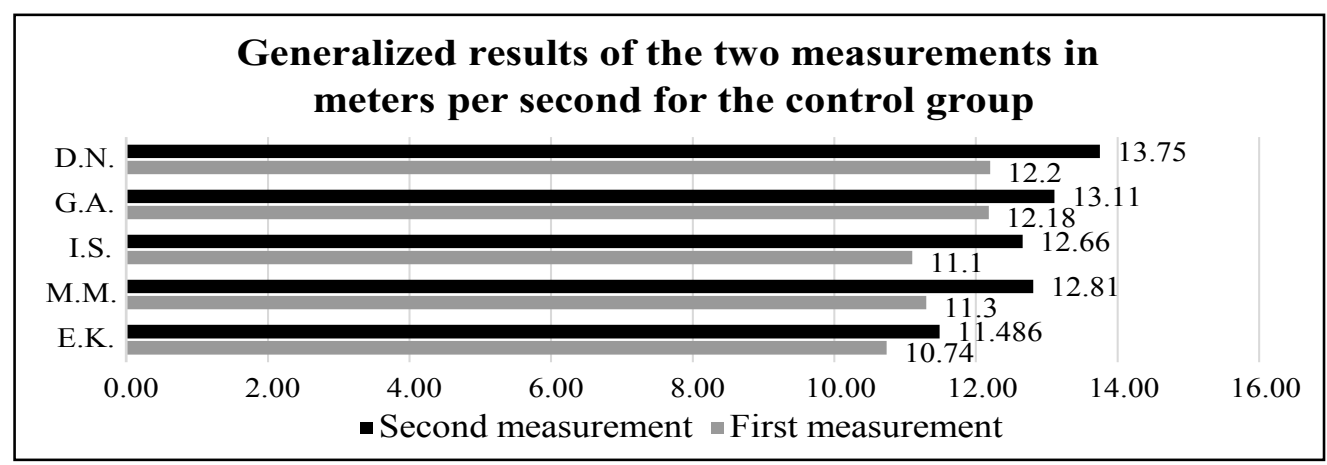

Figure 6. Generalized results of the two measurements for the control group.

Figure 7 presents the generalized values observe an improvement in the average maxiof speeds measured for the test group before mum kick speed by $1.88 \mathrm{~m} / \mathrm{s}$. and after applying the methodology. Here, we

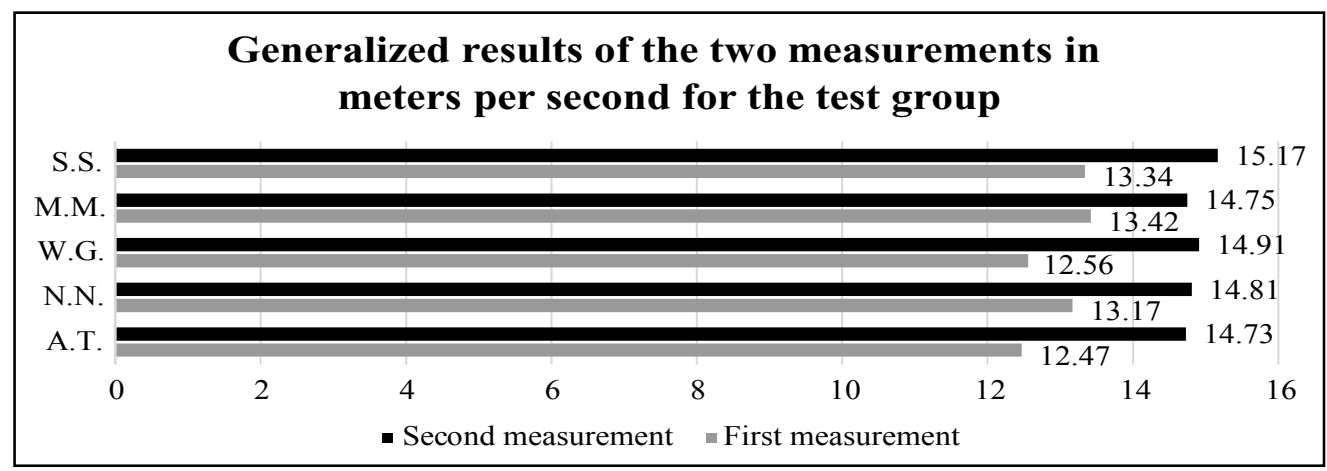

Figure 7. Generalized values of speeds measured for the test group

In order to illustrate the progress of the a comparison between the achieved results two groups more clearly, Figure 8 presents of the two groups for the period of training.

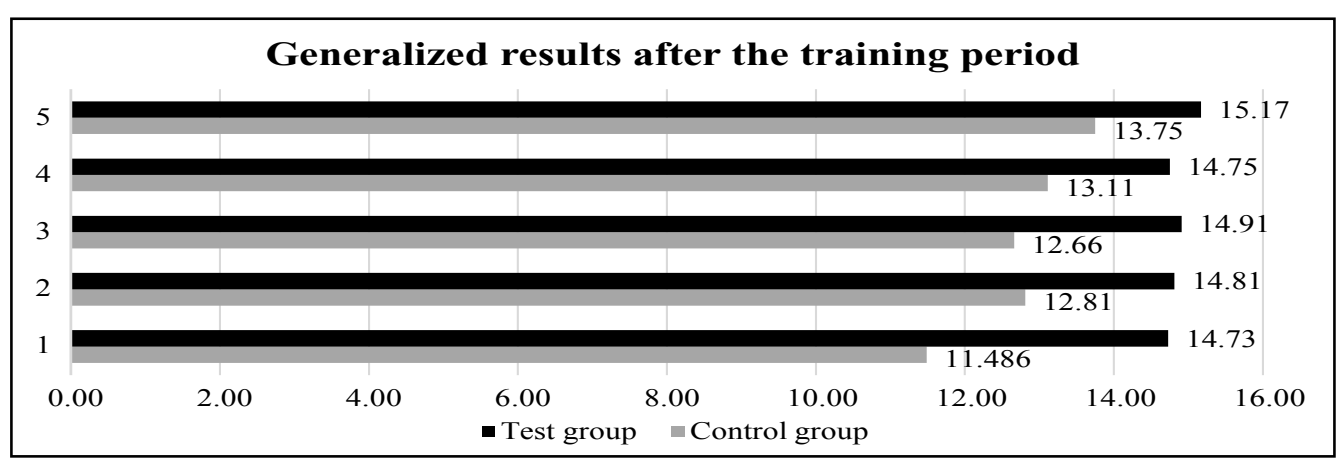

Figure 8. Generalized results after the training period

As Table 4 indicates, the average speed speeds of the two groups is $2.11 \mathrm{~m} / \mathrm{s}$ in faof the test group is significantly higher than vor of the group that used the experimental that of the control group. Respectively, the methodology. difference between the average maximum

Table 4. Results of the variance analysis

\begin{tabular}{ccc}
\hline Indicator/Group & Control Group & Test Group \\
\hline$\overline{\mathbf{X}}$ & 12.763 & 14.874 \\
$\mathbf{S}$ & 0.827 & 0.180 \\
$\mathbf{V \%}$ & 6.482 & 1.208 \\
\hline
\end{tabular}


To calculate $\mathrm{V} \%$ (the coefficient of variation) we needed to calculate the standard deviation S. The variation coefficient was obtained by applying the following formula:

- The coefficient for the control group is $6.482 \%$.

- The coefficient for the test group is $1.208 \%$.

- It may be concluded that the survey is highly uniform, since V\% does not exceed $10-12 \%$.

\section{DISCUSSION}

The mae geri kekomi (front kick in the trunk) was of $15.76 \pm 5.45 \mathrm{~m} / \mathrm{s}$, but the mae geri keage (in the face) was faster, with $19 \mathrm{~m} / \mathrm{s}$ (Marques, 2014). The mae geri without information about the target of the attack was of 9.9 to $19.3 \pm 1.49 \mathrm{~m} / \mathrm{s}$ (Diacu, 2003). The mawashi geri kekomi (semicircular kick with back keg in the trunk) had linear velocity of $3.05 \pm 0.21$ to $8 \pm 3.24 \mathrm{~m} / \mathrm{s}$, but the mawashi geri keage (back leg in the face) the linear velocity was of $3.05 \pm 0.21$ to $7.58 \pm 0.34 \mathrm{~m} / \mathrm{s}$ (Emmermacher et al., 2007). However, the mawashi geri keage with preparatory phase of the kick equal to the mae geri, had better linear velocity $(7.95 \pm$ $0.27 \mathrm{~m} / \mathrm{s}$ ) than the traditional mawashi geri keage $(7.58 \pm 0.34 \mathrm{~m} / \mathrm{s})$ described by Nakayama (Nakayma, 2012).

The mawashi geri without information

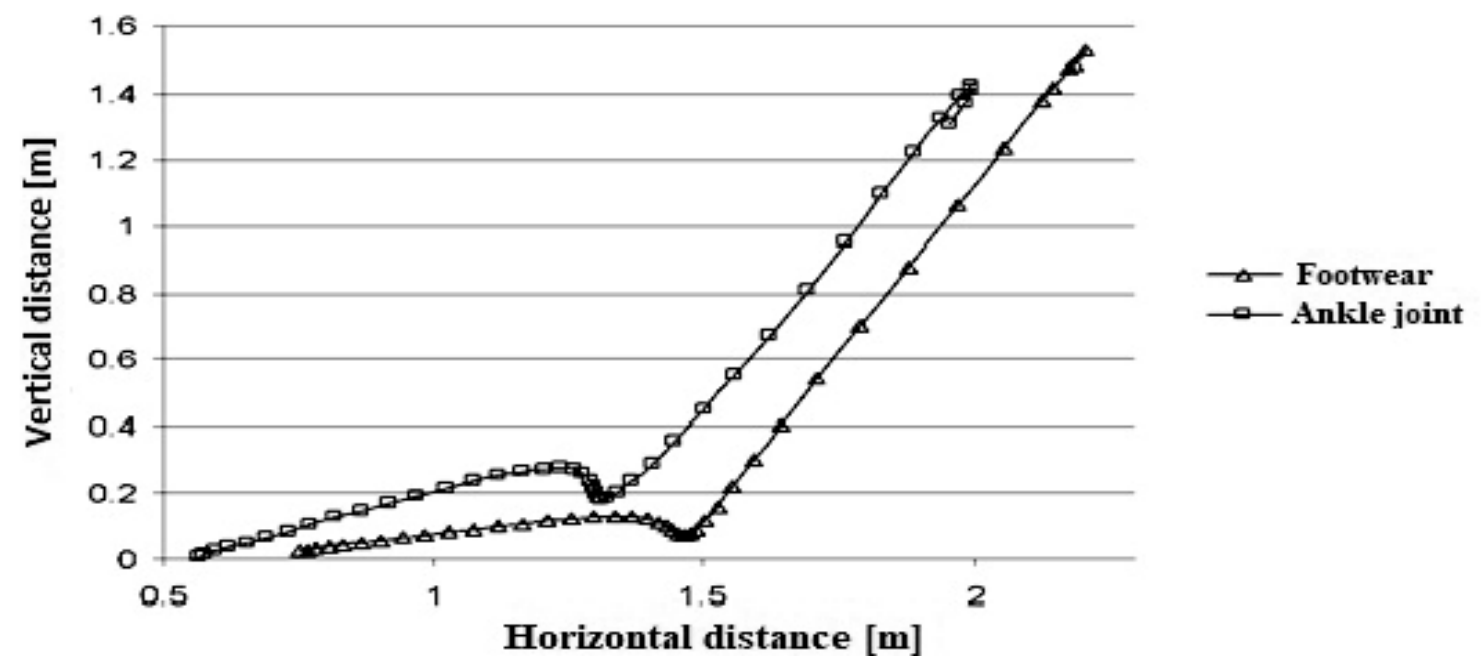

Figure 9. Trajectory of the distal end of the cinematic chain in the case of front-leg kick with a forward step about the target of the attack was of 9.5 to 11 $\mathrm{m} / \mathrm{s}$. Others kicks the karate literature determined the linear velocity, the results were the following: 9.9 to $14.4 \mathrm{~m} / \mathrm{s}$ of the yoko geri (side kick) (Diacu, 2003), $2 \mathrm{~m} / \mathrm{s}$ of the yoko geri kekomi, $41 \mathrm{~m} / \mathrm{s}$ of the yoko geri keage (Gianino, 2010) and 10.6 to $12 \mathrm{~m} / \mathrm{s}$ of the ushiro geri (back kick) (Diacu, 2003)

In order to perform Kizami Mawashi Geri successfully the athlete needs to use an attack transition move. These preparatory motions greatly contribute to effectiveness of the kick's execution. The specific point here is the ability to shorten the distance to the opponent quickly, which is a major task of technical and tactical nature. By exerting pressure onto the underlying surface the competitor increases the linear velocity of his/her own center of body mass in the direction of the opponent and thus utilizes two important advantages: shortening the time for attack and adding extra speed to the attacking surface that will execute the technique.

The spatial structure of the trajectory of the distal end of the cinematic chain in the case of front-leg kick with a forward step (Figure 9) that can be approximated to a straight line in the second phase of the motion, unambiguously illustrates the great technical mastery of execution. 
Figure 10 illustrates the trajectories of the distal end of the cinematic chain in the case of performing the kick from a fixed position. In general, when performing a kick with the real leg, the transitions from one phase to the next are clearly expressed by the presence of an in- flex point in the trajectory graph. The smoothness of the trajectory and a more precise motion in space of the active leg can be achieved by providing a more stable position of the center of body mass, which in turn is provided by the pivoting leg (Penov, 2014).

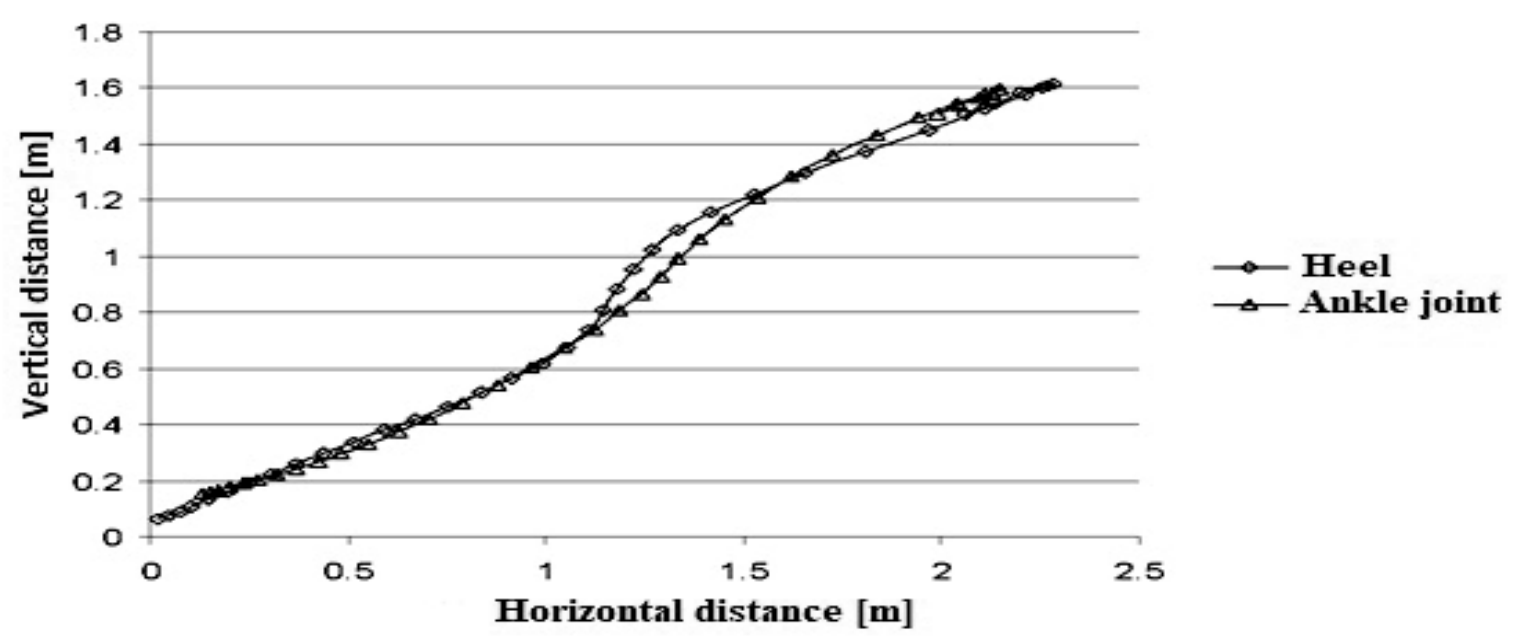

Figure 10. Trajectory of the distal end of the cinematic chain in the case of performing the kick from a fixed position (Mawashi Geri Chudan)

A stable spatial and phase structure of performing the kick predetermines the specifics and the speed qualities of a competitor. Therefore, speed parameters prove to be a major biochemical characteristic (Stanchev and Hristov, 2014).

\section{CONCLUSIONS}

1. The parameter analysis of the speed of the front-leg kick (Kizami Mawashi Geri), as well as the application of the experimental methodology aimed at improving the speed of this kick have brought about observable positive results.

2. Improving the speed of kicks in karate is of great significance in offensive techniques because attacks at higher speeds are harder to block by the opponent, which in turn, leads to winning the match.

3. Following the analysis of the front-leg kick speed (Kizami Mawashi Geri), we observed that this speed is of great importance for the contender, who needs to choose the best attack during the sports match.

4. The improvement of the speeds between the attempts of both groups is credible, which proves that the speed measurement and the video analysis applied can be used in the sports training of karate practitioners and will contribute to improving their sports skills.

\section{REFERENCES}

Bishop, M. (1989). Okinawan Karate: Teachers, Styles and Secret Technique, $A \& C$ Black, First edition, pp. 153 - 166.

Cynarski, W.J., Wajs, W., Vencesbrito, A. (2014). Improving the movements of basic karate techniques with the use of motion capture and mathematical modeling. The concept of a research project. Ido Movement for Culture. Journal of Martial Arts Anthropology, Vol. 14, № 1, pp.39-53.

Diacu, F. (2003). On the dynamics of karate, PIMS, Pi in the Sky № 6, pp. 9-11.

Emmermacher, P., Witte, K., Potenberg, J. 
(2007). Different variations of the karate technique mawashi geri. $25^{\circ}$ International Symposium on Biomechanics in Sport Ouro Preto, MG, Brazil, pp. 289-292.

Gianino, C. (2010). Physics of karate: kinematics analysis of karate techniques by a digital movie camera. Lat Am J Phys Educ, Vol. 4, № 1, pp. 132-34.

Habersetzer, R. (1998). Ko-Budo, Oruzhie Okinavii, Tirasop, Modus, pp. 230-254.

Higaonna, Morio, (1985). Traditional karate do Fundamental Techniques, Vol. 1, Japan Publications, pp. 17-20.

Hristov H., Stanchev N. (2014). Kinematik analysis on the "Shiko" exercise in sumo, 9th EIEP European congress, 7th International scientific congess "Sport, Stress, Adaptation", book of abstracts, 9-12. 10. 2014, Sofia-Bulgaria.

Iliev, I. (2016). Individual training of athletes in wrestling to increase the level of motor skills. Scientific Conference "Challenges and Prospects for Sports Science”, "Specifics of Preparation in Different Sports Courses", Dept. of Heavy Athletics, Boxing, Fencing and Sport for All, Sofia, pp. 65-67.

Marques Junior, N. (2014). Scientific evidences about the fight of the shotokan karate of competition, Brazilian Journal of Exercise
Physiology and Prescription, pp. 400-417.

Nakayma, M. (2012). O melhor do karate-fundamentos. vol. 2, $9^{\mathrm{a}}$ ed., São Paulo: Cultrix, pp. 108-109.

Penov, R. (2014). Analysis of Men's Finals Recordings at the 22nd World Karate Championship (WKF), Bremen, Ch., № 2, pp. 47-53.

Pinto Neto, O., Magini, M., Saba, M. (2007). The role of effective mass and hand speed in the performance of kung fu athletes compared with nonpractitioners. Journal of Applied Biomechanics, Vol. 23, № 2, pp.139148.

Rathee, N., Magnes, J., Davis J. (2014). Kinematics of board breaking in karate using video physics and human performance. European Scientific Journal, Vol.10, № 12, pp. 338-348.

Stanchev, N., Hristov, H. (2014). Structure and biomechanical analysis of the racing technique by gripping the opponent's belt in the sport sumo, Sports and Science, Special issue №2, pp. 5 .

Tabben, M., Coquart, J., Chaabène, H., Franchini, E., Ghoul, N., Tourny, C. (2015). Time-motion, tactical and technical analysis in top-level karatekas according to gender, match outcome and weight categories. Journal of Sports Science, Vol. 33, № 8, pp. 841-849.

\section{Corresponding author:}

Radoslav Penov Department „Wrestling and Judo” National Sports Academy ,Vassil Levski” Studentski grad, 21, Acad. Stefan Mladenov Str. Sofia 1700, Bulgaria E-mail: fighters.nsa@abv.bg 